(2)

\title{
LA GUERRA DE MALVINAS (1982) EN LOS IMAGINARIOS SOCIALES Y EN EL TEATRO: PENSAR LAS REPRESENTACIONES A TRAVÉS DE LA DRAMATURGIA SALTEÑA
}

\author{
THE MALVINAS WAR (1982) IN SOCIAL IMAGINARIES AND IN \\ THEATER: THINKING PERFORMANCES THROUGH SALTA'S \\ DRAMATURGY
}

\section{Ricardo Dubatti}

CONICET / Universidad de Buenos Aires, Instituto de Artes del Espectáculo (ricardo.dubatti@gmail.com)

\section{https://orcid.org/0000-0002-0479-9636}

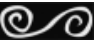

DOI: https://doi.org/10.32621/acotaciones.2020.44.07

ISSN 2444-3948

Resumen: La Guerra de Malvinas (2 de abril-14 de junio de 1982) constituye un acontecimiento indispensable para entender la historia argentina reciente. Consiste en el último conflicto bélico internacional argentino, el único ocurrido a lo largo del siglo XX y uno de los pocos que se ha entablado contra una potencia internacional como el Reino Unido. Al mismo tiempo, su presencia atraviesa de manera fundante tanto la posguerra como la posdictadura, proyectándose hasta la actualidad. El presente artículo se desprende de una investigación mayor (R. Dubatti, 2017a, 2019a) que busca reflexionar sobre las singularidades del teatro como medio para las representaciones (Chartier, 1992, 2007). Para ello, ofrecemos un análisis sobre el estado de la cuestión y los antecedentes de la bibliografía vinculada al tema. Finalmente, proponemos 
un breve análisis del texto dramático de En un azul Je frío (2002) de Rafael Monti, dramaturgo nacido en la provincia de Salta.

Palabras Clave: Imaginarios Sociales, Memoria, Poética Comparada, Posdictadura, Representación.

Abstract: The Malvinas War (April 2-June 14, 1982) is an indispensable event to understand recent Argentine history. It consists of the last Argentine international war conflict, the only one that occurred throughout the twentieth century and one of the few that has started against an international power such as the United Kingdom. At the same time, its presence goes through both post-war and post-dictatorship, projecting until today. This article emerges from a major investigation (R. Dubatti, 2017a, 2019a) that seeks to reflect on the singularities of theater as a means for performances (Chartier, 1992, 2007). To do this, we offer an analyze the status of the issue and the background of the literature related to the topic. Finally, we propose a brief analysis of the dramatic text of En un azul de frío (2002) by Rafael Monti, playwright born in the province of Salta.

Key Words: Social Imaginary, Memory, Comparative Poetics, PostDictatorship, Representation.

Sumario: 1.Estado de la cuestión: Malvinas en los imaginarios sociales, el arte y el teatro. 1.1. Malvinas en los imaginarios sociales. 1.2. Malvinas en diferentes disciplinas artísticas. 1.3. Tesis vinculadas al arte. 1.4. Manuales didácticos. 1.5. Estudios sobre representaciones. 1.6. Malvinas en estudios de conjunto. 2. Acopio y clasificación. 3. Un caso de estudio: En un azul de frío. 4. Conclusión. 5. Obras citadas. 6. Notas.

Copyright: (C) 2020. Este es un artículo abierto distribuido bajo los términos de una licencia de uso y distribución Creative Commons 4.0 Internacional (CC BY 4.0) 
Ricardo Dubatti (Buenos Aires, 1988). Historiador teatral, dramaturgo y músico. Licenciado de la Carrera de Artes (Combinadas) por la Universidad de Buenos Aires. Es becario de CONICET, realiza su doctorado en Historia y Teoría de las Artes (UBA) sobre «Representaciones de la Guerra de Malvinas (1982) y sus consecuencias socioculturales en el teatro argentino (1982-2007): poéticas dramáticas, historia y memoria». Compiló las antologías Malvinas. La guerra en el teatro, el teatro de la guerra (Ediciones del CCC, 2017) y Malvinas II (Ediciones del CCC, 2019). Publicó artículos en KARPA (California State University), $\mathrm{Pa}$ nambi (Universidad de Valparaíso), CELEHIS (Universidad de Mar del Plata), entre otras. Coordinó el dossier «Representaciones de la Guerra

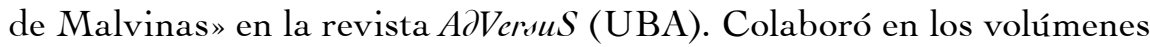
El actor. Arte e Historia (Libros de Godot, México DF), Otras Geografíasl Otros Mapas Teatrales (Campana Sumergida, Polonia) y Poéticas de liminalidad en el teatro I y II (ENSAD, Perú), entre otros.

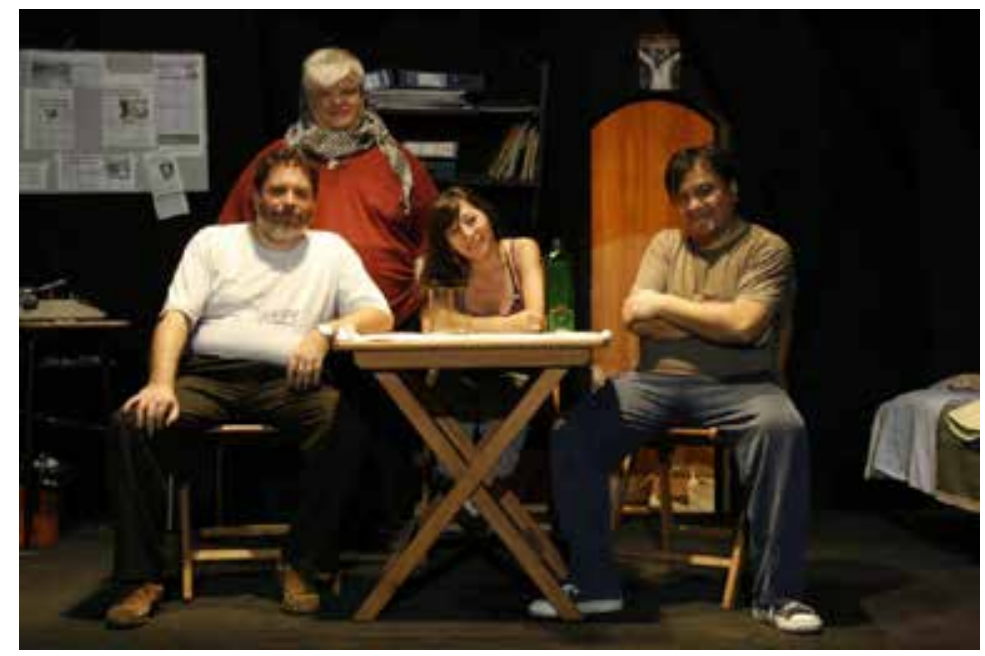

En un azul de frío (2002) de Rafael Monti. Gentileza del Autor. De izquierda a derecha: Rodolfo Elbirt, Rafael Monti, Fernanda Silvia Gonález y Óscar Muñoz. 


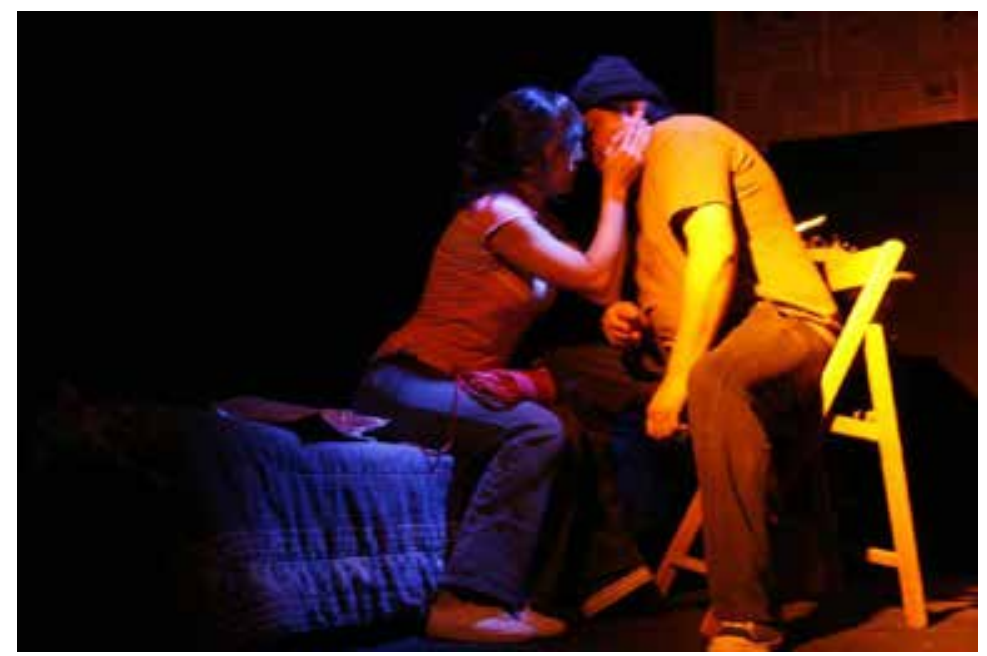

Dos escenas de En un azul Je frío (2002) de Rafael Monti. Gentileza del Autor

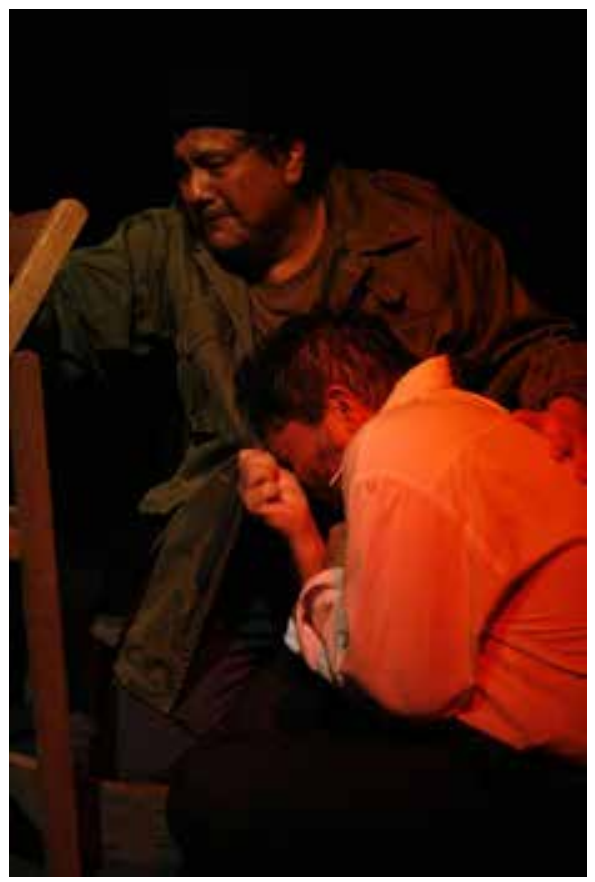


La Guerra de Malvinas (2 de abril-14 de junio de 1982) constituye un acontecimiento indispensable para entender la historia argentina reciente. Consiste en el último conflicto bélico internacional argentino, el único ocurrido a lo largo del siglo XX y uno de los pocos que se ha entablado contra una potencia internacional como el Reino Unido. Al mismo tiempo, su presencia atraviesa de manera fundante tanto la posguerra como la posdictadura, proyectándose hasta la actualidad. El presente artículo se desprende de una investigación mayor (véase R. Dubatti, 2017a, 2019a), que busca reflexionar sobre las singularidades del teatro como medio para las representaciones (Chartier, 1992, 2007). ${ }^{1}$

La causa de la guerra entre Argentina y Reino Unido se centró en la disputa por la soberanía de las Islas Malvinas, Georgias del Sur y Sandwich del Sur. Estos territorios son usurpados en 1833. En las décadas siguientes, las negociaciones se resumen en reiterados reclamos de Argentina ${ }^{2}$ y una dilación sistemática por parte del Reino Unido (Gamba, 1984). El 2 de abril de 1982 el gobierno argentino de facto lanza el Operativo Rosario con el fin de recuperar provisoriamente las islas y así obligar al gobierno europeo a negociar (Túrolo, 1983). Si bien en principio el operativo resulta exitoso, finalmente Argentina debe realizar una guerra para la cual no tenía ningún plan estratégico previo (Balza, 2014). Argentina se rinde luego de 74 días, con un total de 649 bajas.

La Guerra de Malvinas, con sus resultados y efectos, es un hecho clave para la historia reciente argentina. A nivel político, marca un punto de quiebre tanto para el gobierno militar - ya en proceso de declinación - como para la sociedad argentina (Guber, 2001; Lorenz, 2012, entre otros). Debido al fuerte impacto simbólico y psicológico (Escudero, 1997), la transición pactada que la Junta Militar proyectaba se transforma en un traspaso de poder por colapso (E. López, 2007: 19). A nivel social, la violencia tanto de la guerra como de la dictadura que la impulsó posiciona a la memoria en un rol preponderante en la posdictadura (Cattaruza, 2012; J. Dubatti, 2012c), especialmente como medio para evitar que las tragedias del pasado se repitan.

Aún hoy la guerra se halla fuertemente arraigada en el imaginario social argentino. Esto se debe a que opera como una ausencia presente (Jelin, 2002) que se reactiva constantemente debido a que muchos procesos y efectos de la guerra siguen ocurriendo (Agamben, 2000). ${ }^{3}$ En este sentido, «Malvinas» - tanto la Guerra como la Causa- es un territorio de lo no decible (Mancuso, 2010), que ofrece una lejanía (Stiegler, 
2012) o una silueta donde cada individuo puede proyectar sus impresiones personales (Gamerro, 2012). A causa de esto, la guerra se manifiesta en una multiplicidad de lecturas que dificultan la articulación de una interpretación histórica orgánica.

Sin embargo, consideramos que tal multiplicidad ofrece herramientas para pensar la Guerra de Malvinas. A través de la activación de la memoria como trabajo (Jelin, 2002), el teatro hace posible la yuxtaposición de perspectivas diferentes (R. Dubatti, 2019a). Para ilustrar algunas de las problemáticas de esta multiplicidad proponemos, en primer lugar, examinar de modo panorámico el estado de la cuestión de la Guerra de Malvinas en los imaginarios sociales y el teatro. En segundo, señalamos algunos de los desafíos a la hora de relevar el corpus de nuestra investigación. Finalmente, presentamos brevemente un caso ejemplar: En un azul de frío (2002) de Rafael Monti, dramaturgo salteño.

1. Estado de la Cuestión: Malvinas en los imaginarios sociales, EL ARTE Y EL TEATRO

En una entrevista, Carlos Gamerro sugiere que «[l]a Guerra de Malvinas fue la construcción ficcional más elaborada de la historia argentina del siglo XX» (2008: s/d). Esto es indudablemente cierto para el caso del teatro, debido a que en nuestra recopilación y acopio ya hemos reunido más de 100 textos dramáticos vinculados a la guerra (R. Dubatti, 2019a, 2019b). La afirmación de Gamerro también es pertinente para el caso de la bibliografía general sobre las Islas Malvinas y la Guerra de Malvinas. ${ }^{4}$ No obstante, la cantidad de materiales disponibles sobre la presencia de la Guerra de Malvinas en las artes y la cultura es cuantitativamente menor.

A continuación enumeramos y analizamos algunos de los materiales bibliográficos que nutren nuestra investigación. Para su presentación, los hemos dividido de acuerdo a rasgos comunes o temáticas comunes. La selección busca ofrecer un panorama de los diversos enfoques que han suscitado los estudios sobre la guerra, al tiempo que se propone visibilizar materiales para futuras investigaciones. 


\subsection{Malvinas en los imaginarios sociales}

¿Por qué Malvinas? De la causa nacional a la guerra absurda (2001) de Rosana Guber, Sal en las heridas. Las Malvinas en la cultura argentina contemporánea (2007) de Vicente Palermo y Las Guerras por Malvinas (2012; originalmente publicado en 2006) de Federico Lorenz ofrecen una lectura sobre los imaginarios sociales vinculados con la guerra.

El texto de Guber focaliza en las problemáticas del imaginario nacionalista sobre el que se construye y se articula la Causa Malvinas, contexto en el que debe ser pensada la guerra. Así, de su trabajo se desprende la idea de Malvinas como símbolo de potencial unidad nacional. Si la usurpación de 1833 extrae un territorio que deja incompleta a la Nación como ente abstracto dado por natural, su ausencia marca no sólo un daño vigente sino también una potencial restitución de ese carácter totalizante, reflejada en la promesa de volver a ser una nación «completa» una vez que ese territorio sea definitivamente restituido.

Palermo, en contraste, propone una lectura crítica centrada en la guerra como un territorio conflictivo proyectado hacia el presente de manera obsesiva. De este modo, examina las raíces nacionalistas del hecho histórico, pero desde la actualidad (en 2007), cuestionando el «encono» por los hechos del pasado. De esta manera explícitamente toma distancia de la reivindicación de la guerra como medio de reclamo y busca evidenciar las «falsas promesas del nacionalismo», especialmente en sus consecuencias a futuro.

El trabajo de Lorenz describe diferentes problemáticas de la posguerra, especialmente aquella vinculada con las vivencias de los excombatientes y su situación a la hora de reinsertarse en la sociedad luego de combate. Las islas Malvinas aparecen en esta lectura como un territorio donde se proyectan los valores de lo nacional, pero desde una perspectiva menos simbólica y más pragmática. Desde este ángulo, Lorenz propone pensar los efectos de la posguerra en el presente con el fin de comprender un acontecimiento marcado por la inversión de valores, donde la violencia del aparato represivo ilegal del gobierno de facto se proyecta hacia la violencia legítima del combate.

Estos tres trabajos ofrecen lecturas muy diferentes sobre la guerra en los imaginarios de la sociedad, formando un panorama valioso para analizar prácticas sociales y culturales como las del teatro. Sus lecturas sobre el nacionalismo sugieren a su vez una de las problemáticas de la 
guerra: la divergencia de conceptos sobre los cuáles examinar los hechos del pasado reciente. Esto se manifiesta especialmente en el libro de Palermo, que realiza un juicio de valor sobre los hechos que analiza e intenta diseccionar.

\subsection{Malvinas en diferentes disciplinas artísticas}

Vinculadas con el estudio particular de las artes, resultan relevantes las investigaciones realizadas por Bernard McGuirk (Falklands Malvinas. An unfinished business, 2007) y Julieta Vitullo (Islas Imaginadas. La Guerra de Malvinas en La Literatura y el Cine Argentinos, 2012). Estos dos trabajos se nutre a su vez algunas propuestas anteriores, como las de Blanco, Imperatore y Kohan (1993) y Sarlo (1994). En ambos casos el corpus analizado pertenece centralmente a la literatura, el cine y sus cruces productivos. Si bien el teatro aparece como referencia (incompleta) en estos trabajos, no es atendido ni específicamente (no hay un trabajo centrado ni exhaustivo sobre el tema teatral) ni en su singularidad poética (la dramaturgia como lenguaje).

Vitullo hace mención de algunas piezas teatrales, pero opta por focalizar en los ejes de la épica, la paternidad y la deserción en la literatura y el cine. A su vez, las obras dramáticas que señala aparecen más bien vinculadas a figuras de importante producción a nivel literario como Carlos Gamerro, Griselda Gambaro y Vicente Zito Lema. McGuirk otorga un espacio más extenso al análisis de obras teatrales, pero estas también se encuentran enfocadas desde el cruce con novelas, cuentos, poesía y, especialmente, películas. Estudia en simultáneo textos argentinos y británicos y analiza casos, aunque sin ofrecer una lectura de corte inter o transnacional.

En este terreno, son significativos también los aportes de Graciela Mantiñán («'A vos te falta Malvinas'. Señales de identidad en el relato testimonial de la guerra de Malvinas (1982- 2005)», tesis de Maestría de Literaturas Española y Latinoamericana, FFyL, UBA) y Lara Segade ( La guerra en cuestión: relatos de Malvinas en la cultura argentina 1982-2012», tesis doctoral Área Letras, UBA), trabajos inéditos al día de la fecha pero disponibles en espacios digitales. En ambos casos, se emplea la noción de «relato» como concepto unificador con el fin de 
realizar una puesta en común de objetos de estudio heterogéneos. En ambos casos, el énfasis se halla en la narrativa testimonial.

En cuanto al caso específico del teatro, mientras que Vitullo, Mantiñán y McGuirk no proponen ningún inventario exhaustivo de las obras teatrales que refieren a la guerra, Segade observa la numerosa producción que existe dentro del campo teatral, especialmente hacia el trigésimo aniversario de la guerra, en 2012. A pesar de ello no la sistematiza.

\subsection{Tesis vinculadas al arte}

En 2009 se defiende la tesis Masculinidades en transición: La guerra de las Malvinas en la literatura y el cine, escrita por Paola Belén Ehrmantraut, en la universidad Washington, en Saint Louis, Missouri. En ella, la autora se aproxima a la guerra desde la perspectiva de los estudios de género en el cine y la narrativa. Desde su óptica, «la guerra se presenta como una instancia clave desde la cual explorar, por su carácter de transición, diferentes subjetividades que se corresponden con los dispares sistemas políticos» (2009: 1). Su investigación se divide en cuatro grandes ejes de representaciones: soldados, veteranos, patriotas y ciudadanos. El corpus abarca un espectro amplio, desde novelas emblemáticas como Los pichiciegos (1982) de Rodolfo Fogwill y Las islas (1998) de Carlos Gamerro, hasta filmes como Fuckland (2000) de José Luís Márquez. A pesar de esta variedad de casos, no indaga en el teatro. En 2013 la tesis se publica en una edición abreviada a cargo de ComunicArte, editorial radicada en la ciudad de Córdoba.

Por el contrario, en Tempering Trauma with Humor in Argentine PostDictatorship Theatre: Laughing to Recover, Reimage, Rebuild Marin Elizabeth Laufenberg propone un acercamiento a la historia reciente argentina desde la escena teatral. Para ello estudia diferentes maneras en las que el humor permite confrontar acontecimientos de carácter traumático y se detiene en tres momentos históricos específicos: el «Proceso de Reorganización Nacional» (1976-1983), la Guerra de Malvinas y la crisis económica y social de 2001. Luego de una sintética introducción sobre cada momento, analiza dos piezas vinculadas a cada instancia histórica. En el caso de Malvinas elige las piezas Continente viril (2004) de Alejandro Acobino e Islas de la Memoria. Historias de guerra en la posguerra (2011) de Julio Cardoso. A pesar del valor que tiene su aproximación a 
las nociones de trauma y humor, en la presentación del hecho histórico no ofrece ningún listado ni acopio de piezas teatrales vinculadas a la guerra.

Otra tesis valiosa es Malvinas Myths, Falklands Fictions: Cultural Responses to War from Both Sides of the Atlantic de Laura Linford Williams en 2005. Allí analiza los «mitos» en ambos bandos de la guerra, examinando y contraponiendo casos que producen efectos diferenciados. En primer lugar, analiza obras que perpetúan el nacionalismo: la antología de poesía Nuestros poetas y las Malvinas, de 1983, y la película de televisión The Falklands Play, de Ian Curteis, de 1987. En segundo, examina textos teatrales que «des-mitologizan» hechos de la guerra: Del sol naciente de Griselda Gambaro, 1984, y Sink the Belgrano! de Steven Berkoff, 1986. En tercer lugar, estudia novelas que subvierten mitos oficiales y los tratan de reconfigurar: Las Islas de Carlos Gamerro, 1998, y Swansong (1986) de Richard Francis. Finalmente, dedica un apartado a trabajos que presentan una reconstrucción «ambigua» de los mitos: allí se detiene en Los chicos de la guerra, tanto el libro de testimonios como la película, 1982 y 1984 respectivamente, y el film Tumbledown de Richard Eyre, 1988.

En cuanto a investigaciones actuales vinculadas al teatro, debemos señalar el trabajo de Silvia Araújo, de la Universidad Nacional de la Patagonia San Juan Bosco (UNPSJB), quien estudia la narrativa de Malvinas, con aportes significativos para nuestra investigación en el aspecto de las adaptaciones teatrales (véase por ejemplo Araújo, 2019). Verónica Perera, por su parte, se encuentra estudiando el caso de Malvinas desde la perspectiva del teatro neo-documental y la performance, focalizando en representaciones de la última década.

Finalmente, y si bien no se detienen en el campo del teatro, otras investigaciones vinculadas a la guerra son: la tesis sobre narrativa y cine titulada La guerra de Malvinas y su escritura en clave ficcional de Exequiel Svetliza, investigador radicado en Tucumán, defendida en 2017; el trabajo del equipo de investigación Discurso Social. Lo visible y lo enunciable de la Universidad Nacional de Córdoba, dirigido por María Teresa Dalmasso, donde los investigadores Carolina Casali, Baal Delupi y José Manuel Rodríguez Nieva trabajan la guerra de Malvinas desde una perspectiva socio-semiótica que indaga sobre lo audiovisual. ${ }^{5}$ 


\subsection{Manuales didácticos}

El caso de los manuales didácticos permite ilustrar otra de las problemáticas habituales del estudio de la Guerra de Malvinas: la multiplicidad de lecturas diferentes desde distintas bases epistemológicas. Como sugerimos anteriormente, consideramos que esta variedad - que efectivamente complejiza los procesos de análisis - debe ser pensada desde un signo opuesto. De este modo, es posible enriquecer el trabajo a través del cruce de estudios que hagan posible pensar la guerra en diferentes enfoques y lecturas.

En 2009, el Ministerio de Educación de la Nación publica Pensar Malvinas. Una selección de fuentes documentales, testimoniales, ficcionales y fotográficas para trabajar en el aula. En este tomo se consignan diferentes aproximaciones hacia la guerra. Se dedican extensas secciones a explicar y detallar el contexto histórico y los hechos del combate, pero también se presentan apartados dedicados a los imaginarios de Malvinas antes de la guerra, a la memoria del combate y la relación con la institución escolar. A pesar de no definir el concepto, el volumen incluye un apartado dedicado a las «representaciones» de la guerra. Allí se señalan diferentes casos donde la Guerra de Malvinas aparece en el arte. La sección incluye referencias a la literatura testimonial, al cine, a la narrativa y a la fotografía, pero no se realiza ninguna mención al caso particular del teatro.

El Observatorio Malvinas de la Universidad Nacional de Lanús, ubicada en la provincia de Buenos Aires, publica en 2013 Malvinas en la bistoria. Una perspectiva suramericana. Este manual ofrece una lectura a contrapelo de la historia, proponiendo pensar sus sucesos como parte de la historia «suramericana», es decir, como parte de los procesos de decolonización y liberación del continente americano y sus pueblos. De esta manera ofrece un análisis que va desde 1492 hasta el 2010, tomando tres ejes: la geografía, la historia y la instrucción ciudadana. Pese al minucioso trabajo de presentación de elementos históricos, el volumen, no obstante, no ofrece materiales vinculados a la representación de la guerra en la cultura.

En contraste, Ciccone, Heredia, Irazábal y Suñer editan en 2017 el manual Malvinas en el aula. Una propuesta desde la literatura. Este trabajo apunta a reflexionar sobre la guerra desde la perspectiva de la literatura, centralmente de la novela. Según sus autores, la propuesta responde a 
la toma de distancia que la literatura ha ofrecido para pensar la guerra, priorizando el carácter farsesco por sobre la exhaltación triunfalista o el lamento de la derrota (en explícita referencia al análisis de Blanco, Imperatore y Kohan de 1993). En este contexto, el teatro se hace presente a través de una breve cita del texto dramático de Del sol naciente (1983), escrito por Griselda Gambaro. ${ }^{6}$

\subsection{Estudios sobre representaciones}

En el libro Relatos de Malvinas. Paradojas en la representación e imaginario nacional (2016), compilado por María A. Semilla Durán, se reúnen trabajos de diversa índole, principalmente de investigadores y académicos que se encuentran trabajando actualmente en diferentes universidades fuera de la Argentina. En este volumen, se cruzan distintas perspectivas alrededor de la representación de la Guerra, distribuidas en secciones: a) «Pensar Malvinas»; b) «Leer y escribir Malvinas»; c) «Narrar Malvinas»; d) «Impugnar Malvinas» y e) «Filmar Malvinas». Dentro de esta división el teatro aparece apenas mencionado en tan sólo dos artículos. Victoria Torres analiza sucintamente Del Sol Naciente (1983), de Griselda Gambaro, y Sabine Schlickers dedica dos párrafos a Gurka. Un frío como el agua seco (1988), de Vicente Zito Lema. En todos los casos, el teatro es examinado desde una perspectiva literaria, sin considerar herramientas específicas para el análisis teatral ni sopesar los vínculos particulares entre representación, memoria y teatro.

En 2011 se publica el libro Presencia del «inglés» en el teatro y el cine argentinos: de los orígenes a Malvinas, realizado por Victoria Cox y Nora Glickmann. Como su nombre sugiere, el enfoque está puesto en el cine y el teatro. Si bien no todo el libro está dedicado a Malvinas, resulta sugestiva la posibilidad de pensar al «inglés» — como manera coloquial de referirse al británico, sea cual sea su origen - como una figura recurrente en el arte argentino. En este volumen se incluye un capítulo titulado «Las invasiones inglesas y el conflicto de las Islas Malvinas en el teatro: Sixto Pondal Ríos y Carlos Olivari, Juan Carlos Gené, Griselda Gambaro, Osvaldo Guglielmino» (2011, págs. 83-113). Cox y Gluckmann examinan en este apartado algunos casos donde el teatro ha reflexionado sobre la Guerra de Malvinas. No obstante, las piezas seleccionadas no responden a un criterio explícito. Por el contrario, configuran 
un espectro heterogéneo de obras escritas entre 1936 y 1995, donde se entrelazan textos que trabajan o bien las Invasiones Inglesas o bien la Guerra de Malvinas. El análisis de cada pieza consiste en el señalamiento básico del argumento y algunos procedimientos fundantes. Las autoras no formulan lecturas globalizantes más allá de la relación de la Guerra de Malvinas con las Invasiones Inglesas (habitualmente vinculadas debido a la corriente histórica que piensa a ambos acontecimientos como parte de un mismo proceso anti-colonialista).

Entre otras publicaciones, hallamos el capítulo «Performing Public Memorialization of the Malvinas War» de Noe Montez, que forma parte del libro Memory, Transitional Justice and Theatre in Postdictatorship in Argentina (Southern Illinois University Press, 2017). Allí se indaga sobre las representaciones «públicas» de la Guerra de Malvinas, desde una lectura que busca problematizar los fenómenos de la transteatralización, cruzando textos teatrales como Isla flotante (2014) de Patricio Abadi con actos realizados en ámbitos públicos.

\subsection{Malvinas en estudios de conjunto}

Entre los escasos estudios de conjunto sobre la guerra en el teatro debemos señalar el artículo de Liliana López publicado en Cuadernos Argentina Reciente (2007). Allí López realiza un valioso y extenso inventario de obras vinculadas con la temática de Malvinas. A pesar de su relevancia como registro de un corpus nutrido, el artículo presenta una lectura incompleta. Esto se refleja particularmente en la afirmación de la falta de textos dramáticos cercanos a la guerra (como se puede ver en nuestro corpus, existen numerosos casos; remitimos a R. Dubatti, 2017, 2019a, 2019b). J. Dubatti (2012a) propone un trabajo similar, pero dedicado a los textos dramáticos estrenados en Buenos Aires durante 2012, durante el trigésimo aniversario de la guerra. De este modo, no ofrece una lectura diacrónica de los textos sino que se limita a relevar los casos particulares de dicho año.

En contraste, Soria y Rud (2012) trabajan también alrededor del trigésimo aniversario de la guerra con el fin de pensar de qué maneras se produjo un cambio en la percepción y la producción teatral sobre Malvinas. En este sentido afirman que resulta un desafío analizar los cambios en las representaciones teatrales de la guerra a partir de su proyección 
en el eje diacrónico debido a la proliferación de las representaciones de Malvinas que se produce a partir del gobierno de Néstor Kirchner (2003-2007) y que se continúa durante los mandatos de Cristina Fernández (2007-2011 y 2011-2015).

A nivel académico, se presentan esporádicamente diversos artículos vinculados a obras que se conectan con el tópico de Malvinas. No obstante, en numerosas ocasiones estos trabajos no necesariamente focalizan su análisis en sus relaciones con el acontecimiento histórico, sino que priorizan otros ángulos de análisis. Esto ocurre, por ejemplo, con el artículo de Brenda Werth (2013) sobre Museo Miguel Ángel Boezzio, de Federico León, donde estudia la pieza teatral desde la perspectiva del teatro postdramático y el biodrama, sin desarrollar su vínculo con la guerra. Algo similar ocurre también en los trabajos de Ana Laura Lusnich (2001) y de Marta Contreras (1994a y 1994b) sobre Del ool naciente de Gambaro, donde la guerra no es mencionada y el énfasis se coloca en las relaciones de poder entre protagonista y antagonista.

\section{ACOPIO Y CLASIFICACIÓN}

Como hemos comentado anteriormente, nos encontramos desarrollando un trabajo de búsqueda, recolección y acopio sobre los textos dramáticos vinculados a la Guerra de Malvinas (R. Dubatti, 2017a, 2019a, 2019b). Este representa uno de los ejes centrales de nuestra investigación, ya que es a través de la presencia sostenida de la guerra a lo largo de la posguerra y la posdictadura que se evidencia su vigencia en el teatro. A su vez, es a través del relevamiento del corpus que podemos estudiar la multiplicidad de poéticas desde una mayor exhaustividad. Sin embargo, esto acarrea algunas dificultades, como ya se ha sugerido en el estado de la cuestión antes expuesto.

En primer lugar, el trabajo de acopio implica la organización de un material heterogéneo y producido en múltiples mapas teatrales del país. Esto se refleja en una gran cantidad de materiales diversos que permiten pensar la guerra desde diferentes cartografías, con sus subsecuentes modalidades de producción, recepción y circulación específicas. En este aspecto, el teatro evidencia su carácter radicante (Bourriaud, 2009), marcado por unas coordenadas espacio-temporales específicas. Esto en 
muchos casos implica la necesidad de desplazarse en busca de materiales o de contactarse con investigadores locales.

En segundo lugar, la baja visibilidad del corpus, ya sea teórico o artístico. En muchos casos los textos dramáticos circulan a través de ediciones de autor que representan una tirada muy pequeña. En otros casos, los materiales no se encuentran publicados en ningún formato, sino que circularon únicamente como espectáculos. En este caso es de gran utilidad contactarse con los autores y con bibliotecas especializadas que digitalizan textos teatrales inéditos. Esta baja visibilidad llega a ser tan notoria, que en numerosas ocasiones autores (tanto académicos como dramaturgos) que han trabajado sobre la Guerra de Malvinas nos inquieren acerca de si existe una cantidad de corpus disponible para realizar una tesis.

Debido a esto, hemos incorporado a nuestra investigación la producción de antologías que permitan visibilizar la producción dramatúrgica. $\mathrm{Al}$ momento de redactar este artículo, nos encontramos preparando un tercer volumen, que continúa el trabajo iniciado con Malvinas. La guerra en el teatro, el teatro de la guerra (Ediciones del CCC, 2017) y Malvinas II (Ediciones del CCC, 2019). Estas antología reúnen entre 6 y 8 textos dramáticos referidos a la guerra y configuran un panorama que articula diferentes miradas e interpretaciones sobre los hechos desde la particularidad del teatro. Para ello compilamos textos de diferentes cartografías y momentos históricos, con el fin de proponer un ejercicio de Teatro Comparado (J. Dubatti, 2012b) que permita pensar «lo uno y lo diverso» (Guillén, 1985).

En tercer lugar, el teatro como acontecimiento marcado por la pérdida (J. Dubatti, 2012b), con su correspondiente producción de herramientas de análisis. Al momento de desarrollar nuestra pesquisa, las teorías sobre la escena proliferan, tomando el lugar que en otras épocas ocupaba el análisis textual de la dramaturgia. Así, nos hallamos en un período en el que se multiplican los enfoques que piensan el hecho teatral desde la escena y el cuerpo del actor. En nuestro caso, debido a la dificultad que plantea estudiar ya sea la puesta o los textos espectaculares (De Marinis, 2005) y a la posibilidad de emplear los textos dramáticos como documentos de la historia (Collingwood, 1968) hemos optado por focalizar el estudio en la dramaturgia.

Si, como sugiere Joseph Danan (2012), es posible entender la dramaturgia o bien como un texto pautado previamente o bien como una 
serie de acciones construidas desde la escena, consideramos valioso conceptualizar al texto teatral como un territorio que combina simultáneamente elementos de ambas perspectivas. Es decir, como un texto que se desarrolla para la escena y como una escena que se construye en vistas de un acto comunicacional. Así, todo texto dramático incluye sus propias instrucciones de lectura (Lotman, 1996), construidas como «matrices de representatividad» (Ubersfeld, 1989) que articulan diversos lenguajes no sólo textuales sino también actorales, escenográficos, etc. El texto dramático se transforma de este modo en un hecho textual pero que conserva una potencialidad teatral diferente a las de la narrativa o la poesía.

Finalmente, nos hallamos ante el desafío de articular esos materiales acopiados en categorías que permitan no sólo diferenciar poéticas y modalidades de trabajo, sino también poner en común esos elementos. En algunos trabajos previos (R. Dubatti, 2019a, 2019b) proponemos una división en cinco grupos que nos permiten problematizar las relaciones entre las diferentes poéticas y los hechos históricos. De este modo, proponemos:

GRUPO

\section{DESCRIPCIÓN}

Obras argentinas (escritas, estrenadas en la Argentina) o de creadores argentinos (que escriben, estrenan fuera del país) que desarrollan explícitamente, en formato total o fragmentario, la temática de la Guerra de Malvinas (sus antecedentes, los hechos bélicos, la posguerra) y/o que explicitan su representación de la guerra a través de metatextos. Se incluyen dentro de este grupo poéticas muy diferentes, entre el teatro convencional y el teatro liminal. Este es el grupo más numeroso y complejo a causa de su diversidad, así como también el más relevante para nuestra investigación. 
GRUPO

II

III

IV
DESCRIPCIÓN

Obras argentinas (escritas, estrenadas en la Argentina) o de creadores argentinos (que escriben, estrenan fuera del país) que, sin desarrollar centralmente la temática de la Guerra de Malvinas, incluyen referencias explícitas a sus acontecimientos (preguerra, guerra y/o posguerra).

Obras argentinas (escritas, estrenadas en la Argentina) o de creadores argentinos (que escriben, estrenan fuera del país) que hacen referencia general a la guerra pero no necesariamente refieren en particular a la Guerra de Malvinas. En este grupo ubicamos piezas que particularmente refieren a otras guerras (ya sea de modo literal o a través de un metatexto) y que, metafóricamente, podrían ser leídas desde la Guerra de Malvinas: las Invasiones Inglesas (como parte de las Guerras de Independencia), la Guerra de la Triple Alianza, la I Guerra Mundial, la Guerra Civil Española, etc.

Obras argentinas (escritas, estrenadas en la Argentina) o de creadores argentinos (que escriben, estrenan fuera del país) y de autores extranjeros (escritas, estrenadas fuera de la Argentina) escritas antes de la Guerra de Malvinas, pero resemantizadas por los artistas o los espectadores a través de procesos de reescritura / puesta en escena / recepción en la Argentina de los años de la guerra y la posguerra.

Obras de autores extranjeros (escritas, estrenadas fuera de la Argentina, o a posteriori representadas en el país por elencos extranjeros o nacionales) que desarrollan central y explícitamente la temática de la Guerra de Malvinas, y/o que explicitan esa relación a través de metatextos. 
Si bien estas categorías son permeables y se encuentran siempre en proceso de reactualización y revisión debido a la constante incorporación de nuevos materiales, consideramos que son de utilidad para poner en diálogo micropoéticas muy diferentes que toman elementos comunes de un campo referencial específico (véase por ejemplo el análisis realizado en R. Dubatti, 2017b).

En el siguiente y último apartado de este trabajo, presentamos un caso de estudio con el fin de ilustrar algunas de las posibilidades a través de la cuales la guerra es interpelada por y desde el teatro.

\section{UN CASO DE ESTUDIO: EN UN AZUL DE FRÍO}

Rafael Monti escribe En un azul Je frío en 2002. Ese mismo año es seleccionada en el Certamen Nacional de Dramaturgia organizado por Argentores y se estrena el 27 de agosto en la Ciudad Autónoma de Buenos, bajo la dirección de Susana Torres Molina. Dos años más tarde se estrena en la provincia de Salta, donde realiza más de once temporadas consecutivas. Ese mismo año es seleccionada para la Fiesta Provincial del Teatro. En 2017 se estrena en Río Gallegos, provincia de Santa Cruz, en una producción conjunta entre las compañías Los Polonios y Sin Anestesia. El texto dramático se publica en 2006 en un volumen del Instituto Nacional del Teatro, junto a otros escritos de Monti.

Dentro del corpus de poéticas vinculadas a la Guerra de Malvinas, ubicamos esta pieza en el Grupo I (R. Dubatti, 2017a, 2019a), debido a que desarrolla la temática de Malvinas de manera explícita. Se trata de un caso singular, ya que es una de las obras del corpus que más temporadas ha realizado y que más ha circulado. A su vez, presenta un recorrido por diferentes cartografías de la Argentina y ha recibido diversos reconocimientos debido a su valor memorialista. Como muestra de esto, el espectáculo no sólo es declarado de Interés Cultural por la Secretaría de Cultura de la Provincia de Salta, sino también para la Memoria por la Asociación de Veteranos de Guerra de Malvinas — filial Salta.

La pieza gira en torno de tres personajes: Martín — un «periodista autodidacta» con una esposa desaparecida (2002, pág. 1) -, ${ }^{7}$ Coco — «ex combatiente de Malvinas, algo trastornado pero con momentos lúcidos» (pág. 1) - y Alba - empleada doméstica-. La acción transcurre en la 
casa de Martín, donde Coco está hospedado. Ellos viven solos hasta que llega Alba, contratada por el excombatiente en el mercado. A pesar de la tensión que implica su llegada, Alba termina quedándose. A medida que avanza la acción Martín y Coco se interesan en ella, que termina yéndose a Buenos Aires «a probar suerte» (pág. 16). Finalmente Coco también deja la casa, ante la mirada impotente de Martín.

A lo largo de doce secuencias separadas por transiciones, se desarollan situaciones cotidianas donde se presentan problemáticas de la posguerra: la soledad, la locura, las responsabilidades sociales, la voluntad de evasión y el olvido. Como observa Marcela Sosa (2002), la obra articula un «efecto de realidad» que remite a la poética del «realismo reflexivo» (Pelletieri, 1997). A través de procedimientos de esta poética, Monti apunta a construir una ilusión de contigüidad entre escena y vida cotidiana. Así, recurre a acciones, al uso de lenguaje coloquial y a espacios evocados que remiten al día a día salteño, pero también a referencias que reenvían a la crisis económica de 2001. De este modo, el espectador es impulsado a unir la escena con sus vivencias de la vida cotidiana, proyectando los problemas de la obra hacia su actualidad inmediata. ${ }^{8}$

$\mathrm{Al}$ aproximarse deliberadamente la escena y la audiencia, el ángulo semántico cobra un mayor espesor. Esto se orienta ya a partir del título de la pieza, frase de extraída de "Cafetín de Buenos Aires», tango escrito por Enrique Santos Discépolo en 1948. Mediante esta referencia, Monti acota la interpretación de su texto, ya que el tango habla de la nostalgia y de la derrota, pero simultáneamente sugiere la idea de un tiempo congelado, detenido. Como se puede apreciar a lo largo de la pieza, sus tres protagonistas se encuentran atrapados en un ámbito que los oprime, ya sea porque el pasado les persigue o porque la sociedad no les permite desear algo más allá.

Los personajes poseen limitaciones diferentes. Coco no puede superar un pasado traumático que continúa retornando no sólo por su intensidad, sino porque la sociedad no cumplió con las promesas de contención. Alba se halla atrapada debido a que no debe hacer cosas que salgan de su rol de mujer, especialmente en un marco social machista - donde los piropos son lo último que queda de «poesía», como sugiere Martín (pág. 4)—. Finalmente, Martín no quiere salir de ese tiempo congelado. Si bien su motivación es ayudar tanto a Coco como a Alba $-\mathrm{y}$ los otros «locos» que Coco trajo antes-, su perspectiva es la de aceptar las cosas 
y adaptarse, como ocurre con su esposa, Laura, desaparecida durante la dictadura cívico-militar. ${ }^{9}$ Así, la casa opera como una suerte de limbo, una zona donde los personajes esperan.

El aparente suicidio de Coco al final de la obra introduce un doble efecto que refuerza esta idea al tiempo que estimula al espectador a desarrollar un rol activo. Por un lado, marca un movimiento en falso. Asumir «naturalmente» - como Martín— que el «loco de la guerra» se suicida, impulsa a cuestionar cómo se intuye la guerra. Al no haber ocurrido el suicidio -ni siquiera como tentativa-, el espectador debe retrotraer su interpretación y compararla con la patética respuesta de Martín, que en lugar de lamentar la pérdida de su amigo, se asume abandonado una vez más. Por otro lado, como sugiere Coco, «no, cómo [Laura] va a estar muerta [...] Cuando venga decile que no me pasó nada... Que no estoy loco, que estoy un poco cansado de acá... (Se señala la cabeza.) Y de acá. (Se señala el corazón.) Que yo tampoco me morí» (pág. 18). Esta frase delinea una idea que marca la pieza y se conecta con el tiempo detenido: no hace falta estar muerto para no estar vivo.

La Guerra de Malvinas se interpreta así como un acontecimiento suspendido en el tiempo, que aún está presente porque sigue produciendo dolor a nivel individual y porque continúa siendo una deuda social. Coco afirma que la guerra es «un negocio absurdo» (pág. 2), sin embargo, Martín conecta los hechos del pasado con otra guerra: «la que peleamos todos los días con la peor de las armas: la de no creer en nada ni en nadie. Ni en uno mismo» (pág. 2). La violencia extra-ordinaria de la guerra se complementa con otra violencia, la ordinaria, la del día a día. Malvinas aparece conectado con la dictadura y de la crisis del 2001 porque son parte de un mismo proceso.

Los soldados aparecen como traicionados, dejados de lado tanto por el poder como por la sociedad argentina. Como sugiere Coco: «Treinta millones de promesas me hicieron. Treinta millones de argentinos nos dijeron que íbamos a ganar. Pero no ganamos. Y cuando volvimos perdedores, treinta millones nos prometieron laburo y pensiones... porque éramos héroes. Allá quedaron las tumbas. Y acá volvimos los muertos que se olvidaron de enterrar» (pág. 13). A través del topic (Eco, 1993) del «loco de la guerra», entendido específicamente como resultado de esa traición y de la violencia del combate, libera a Coco de su responsabilidad en los hechos y colocan la lectura crítica sobre la respuesta social ante la guerra. 
La memoria de la guerra se sugiere atravesada por el dolor: tanto olvidar como recordar devienen imposibles, pero en cualquier caso el sufrimiento sigue ahí. Sin embargo, la sociedad ya decidió tomar el camino de la evasión y el olvido, por lo que la memoria es más dolorosa y necesaria. De manera sugestiva, a pesar de no ofrecer indicios precisos acerca de qué depara su futuro, tanto Alba como Coco salen de la casa al final de la pieza. Esto coloca la mirada sobre Martín, que mira «derrotado» (pág. 18) cómo el ex combatiente parte. A la manera canónica del realismo reflexivo, Martín queda expuesto entonces como síntesis de una clase media que opta por evadirse cada vez que tiene la oportunidad de enfrentar sus problemas. Simultáneamente, Alba lleva un hijo suyo en el vientre, lo que puede interpretarse desde dos ángulos: o bien la historia promete repetirse o bien una parte de él ha salido de la casa. En cualquier caso, es trabajo exclusivo del espectador decidir qué examen merecen las acciones de Martín.

A través de estos recursos que hemos enumerado, En un azul de frío propone una lectura de la Guerra de Malvinas que abre nuevas interpretaciones y preguntas. Monti utiliza la dramaturgia para interrogar acerca de los roles de la sociedad tras la batalla, ya que quienes tienen que responder no son los excombatientes, sino la sociedad que los lleva a la guerra y luego no rinde cuenta de sus responsabilidades. En este sentido, la locura parece responder no tanto a la guerra en sí misma sino al hecho de llevar la violencia de la guerra adentro, sin contención alguna. ${ }^{10}$ La pregunta que parece atravesar a Coco es: ¿cómo no enloquecer ante el rechazo de la sociedad? La conexión entre escena y vida cotidiana, apunta entonces a revelar las evasiones, las ausencias y las deudas que todavía se entablan. Monti apunta así no tanto a recrear los hechos del pasado sino a crear los actos del futuro.

\section{Conclusión}

Mediante el presente trabajo hemos intentado ofrecer una mirada general sobre la diversa bibliografía de la Guerra de Malvinas en los imaginarios sociales y el teatro. Los materiales que hemos relevado presentan miradas y metodologías diversas que permiten delinear algunos ejes comunes y nos posibilitan pensar la guerra desde perspectivas múltiples en tensión. Consideramos en este aspecto que la dramaturgia ofrece no 
sólo un terreno de registro de la memoria - parcial, que reclama de manera persistente su reactualización en la escena- sino también un medio para la estimulación de la memoria como trabajo (Jelin, 2002). Si la dramaturgia se presenta debido a la ausencia de los cuerpos, aun así es posible ver su potencial como ámbito de memoria que forma de apertura a nuevas miradas. La dramaturgia construye, como hemos visto a partir de la pieza escrita por Rafael Monti en el último apartado, no solo voces del pasado, sino también nuevas aproximaciones al presente y el futuro.

\section{Obras Citadas}

AA.VV. (1998). Informe Rattenbach. El Jrama de Malvinas. Buenos Aires: Espartaco.

AA.VV. (2016). Relatos de Malvinas. Paradojas en la representación e imaginario nacional, Villa María: Eduvim.

Agamben, Giorgio, Lo que queda de Auschwitz. Homo Sacer III. Valencia: Pre-Textos, 2000.

Araújo, Silvia, «Ficciones de Malvinas: Diálogos, préstamos y tensiones entre el género narrativo y el género dramático». Identidaded, $\mathrm{N}^{\circ} 19$, año 9, marzo, 2019, 18-37.

Balza, Martín, Malvinas. Gesta e incompetencia. Buenos Aires: Sudamericana, 2014.

Blanco, Osvaldo, Imperatore, Andrea y Kohan, Martín, «Transhumantes de neblina, no las hemos de encontrar. De cómo la literatura cuenta la guerra de Malvinas», Espacios, Buenos Aires, 13 de diciembre, 1993.

Bourriaud, Nicolas (2009). Radicante. Buenos Aires: Adriana Hidalgo.

Cardoso, Julio (2013). «La posguerra como campo de batalla». En Cardoso, Julio (comp.) Primer congreso Latinoamericano «Malvinas, una Causa de la Patria Grande». Remedios de Escalada: Universidad Nacional de Lanús, 198-214.

Chartier, Roger (1992). El mundo como representación. Estudios sobre bistoria cultural. Barcelona: Gedisa.

(2007). La historia o la lectura Jel tiempo. Barcelona: Gedisa.

Cattaruzza, Alejandro (2012). «Dimensiones políticas y cuestiones historiográficas en las investigaciones históricas sobre la memoria», Storiografía, $\mathrm{N}^{\circ} 16,71-91$. 
Ciccone, Carlos, Heredia, Julieta, Irazábal, Pedro y Suñer, Nayla (2017). Malvinas en el aula. Una propuesta desde la literatura. Viedma: Universidad Nacional del Comahue.

Collingwood, Robin George (1968). Idea de la bistoria. México: FCE.

Contretas, Marta (1994a). «Diagnosis de la pareja: el samurai y la geisha. Del sol naciente de Griselda Gambaro». En Pereira Poza, S. (ed.) Del rito a la posmodernidad. Santiago: IITCTL, 6981.

(1994b). Griselda Gambaro. Teatro de la Jescomposición. Concepción: Universidad de Concepción.

Cox, Victoria y Glickman, Nora (2011). Presencia Jel «inglés» en el teatro y el cine argentinos: de los orígenes a Malvinas. Buenos Aires: Corregidor.

Danan, Joseph (2012). Qué es la Jramaturgia. México DF: Paso de Gato.

De Marinis, Marco (2005). En busca del actor y del espectador. Comprender el teatro II. Buenos Aires:Galerna.

Dubatti, Jorge (2012a). "Las Malvinas en el teatro argentino: memoria en escena, del testimonio a la metáfora", en La revista del CCC [en línea], Enero/Agosto, nº14/15, 2012a. [citado 2019-

11-12]. Disponible en Internet: http://www.centrocultural. coop/revista/articulo/316/

(2012b). Introducción a los estudios teatrales. Propedéutica, Buenos Aires: Atuel.

(2012c). Cien años de Teatro Argentino. Desde 1910 a nuestros días, Buenos Aires: Biblos.

Dubatti, Ricardo, (2017a), (comp.) Malvinas. La guerra en el teatro, el teatro de la guerra, Buenos Aires: Ediciones del CCC. Incluye «Prólogo. La guerra en el teatro, el teatro de la guerra» (7-21).

(2017b). «La Guerra de Malvinas en la novísima dramaturgia argentina: poéticas de herencia, silencio y herida», revista Conjunto, $\mathrm{N}^{\circ} 184$, julio-septiembre, La Habana.

(2018). (coord.) «Representaciones de la Guerra de Malvinas (1982)», dossier, AəVersus, diciembre, Universidad de Buenos Aires.

(2019). (comp.) Malvinas II. La guerra en el teatro, el teatro de la guerra, Buenos Aires: Ediciones del CCC. Incluye «Prólogo. Teatro de la guerra: corpus de representaciones de la Guerra de Malvinas en textos dramáticos y espectáculos» (7-38). 
(2020). «Teatro de la guerra: aportes al corpus de representaciones de la Guerra de Malvinas en textos dramáticos y espectáculos», Revista Colombiana de las Artes Escénicas, Año $11 \mathrm{~N}^{\circ} 12$, Medellín.

Eco, Umberto (1985). Obra abierta. Barcelona: Planeta-Agostini. (1993). Lector in Fabula. Barcelona: Lumen.

Ehrmantraut, P. B., Masculinidades en transición: La guerra de Las Malvinas en la literatura y el cine, Saint Louis: Washington University, 2009. (2013). Masculinidades en transición: la guerra de las Malvinas en la literatura y el cine. Córdoba: ComunicArte.

Escudero, Lucrecia (1997). Malvinas: el gran relato. Fuentes y rumores en la información de guerra, Barcelona: Gedisa.

Forti, Dardo (2014). Hasta el último día. Logística: la «otra guerra» de Malvinas. Buenos Aires: Atlántida.

Gamba, Virginia (1984). El peón de la Reina. Buenos Aires: Sudamericana.

Gamerro, Carlos (2002). «Tras un manto de neblina», en suplemento Radar de Página 12, 16 de junio. Disponible en línea: https:// www.pagina12.com.ar/diario/suplementos/radar/9-228-200206- 17.html

(2012). «El eterno retorno», en suplemento Radar de Página 12, 10 de junio. Disponible en línea: https://www.pagina12.com.ar/ diario/suplementos/libros/10-4695-2012-06-10.html

Guber, Rosana (2001). ¿Por qué Malvinas? De la causa nacional a la guerra absurda, Buenos Aires: FCE.

Guillén, Claudio (1985). Entre lo uno y lo diversos. Introducción a la literatura comparada, Barcelona: Crítica.

Jelin, Elizabeth (2002). Los trabajos de la memoria, Madrid: Siglo XXI.

Laufenberg, Marin (2017). Tempering Trauma with Humor in Argentine Post-Dictatorship Theatre: Laughing to Recover, Reimage, Rebuild», University of Wisconsin, tesis de doctorado.

López, Ernesto (2007). Cuadernos Argentina Reciente, N4, Malvinas (25 aniversario).

López, Liliana (2007). «La guerra de Malvinas en el imaginario teatral argentino», Cuadernos Argentina Reciente, N4, Malvinas (25 aniversario), $178-183$. 
López, Marcelo (2008). «Pequeña entrevista a Carlos Gamerro, de Marcelo López». No Retornable. Disponible en línea: http://www. no-retornable.com.ar/v2/dossier/gamerro.html

Lorenz, Federico (2009). Malvinas. Una guerra argentina. Buenos Aires: Sudamericana.

(2012). Las guerras por Malvinas. Buenos Aires: Edhasa.

Lotman, Y., La semiósfera I. Semiótica de la cultura y del texto. Madrid: Cátedra / Univeristat de Valencia, 1996.

Lusnich, Ana Laura (2001). «Cambio y continuidad en el realismo crítico de Griselda Gambaro y Eduardo Pavlovsky». En Pellettieri, O. (dir.) Historia Jel Teatro Argentino en Buenos Aires (volumen V). El teatro actual (1976-1998). Buenos Aires: Galerna, 341-352.

Malvinas Observatorio (2013). Malvinas en la historia. Una perspectiva suramericana. Remedios de Escalada: Universidad Nacional de Lanús.

Mancuso, Hugo Rafael (2010). De lo decible. Entre semiótica y filosofía: Peirce, Gramsci, Wittgenstein. Buenos Aires: Editorial SB.

Mantiñán, Graciela (2005). «'A vos te faltan las Malvinas'. Señales de identidad en el relato testimonial de la guerra de Malvinas (1982-2005), tesis de maestría. Disponible en línea: https:// avostefaltamalvinas.wordpress.com/

McGuirk, Bernard (2007). Falklands Malvinas. An unfinished business. Seattle: New Ventures.

Ministerio de Educación Presidencia de la Nación (2009). Pensar Malvinas. Una selección de fuentes documentales, testimoniales, ficcionales y fotográficas para trabajar en el aula. Buenos Aires: Ministerio de Educación Presidencia de la Nación.

Montez, Noe (2017). «Performing Public Memorialization of the Malvinas War». En Memory, Transitional Justice and Theatre in Postdictatorship in Argentina Illinois: Southern Illinois University Press.

Monti, Rafael (2006). Caja de resonancia y búsqueda de la propia escritura. Buenos Aires: Inteatro.

Palermo, Vicente (2007). Sal en las heridas. Las Malvinas en la cultura argentina contemporánea. Buenos Aires: Sudamericana.

Pellettieri, Osvaldo (1997). Una bistoria interrumpida. Teatro argentino moJerno (1949-1976). Buenos Aires: Galerna. 
Rud, Lucía y Soria, Carolina (2012). «La guerra de Malvinas y el teatro 30 años después: entre el teatrealismo y el realismo». Teatro $X X I$, Año 18, No. 32, primavera.

Sarlo, Beatriz (1994). «No olvidar la guerra de Malvinas. Sobre cine, literatura e historia», Punto de Vista, $\mathrm{N}^{\circ} 49$.

Segade, Lara (2014). «La guerra en cuestión: relatos de Malvinas en la cultura argentina (1982-2012)», tesis de doctorado, UBA, inédita.

Sosa, Marcela (2002). "Teatro y sociedad: En un azul de frío de Rafael Monti». Actas VII Jornadas Regionales de Investigación en Humanidades y Ciencias Sociales, Jujuy.

Stiegler, Bernd (2012). La quietud en movimiento. Una breve bistoria cultural de los viajes en y alrededor del cuarto. Buenos Aires: Paidós.

Túrolo, Carlos (1983). Malvinas. Testimonio de su gobernador. Buenos Aires: Sudamericana.

Ubersfeld, Anne (1989). Semiótica teatral. Madrid: Ediciones Cátedra.

Vitullo, Julieta (2012). Islas Imaginadas. La Guerra de Malvinas en la Literatura y el Cine Argentinos, Buenos Aires: Corregidor.

Werth, Brenda (2013). «Ritos Íntimos y Propuestas Éticas en el Proyecto Museos de Vivi Tellas», en Rev. Bras. Estud. Presença, Porto Alegre, v. 3, n 3, septiembre-diciembre, 789-804.

Disponible en línea: http://www.seer.ufrgs.br/presenca

Williams, Laura Linford (2005). «Malvinas Myths, Falkland Fictions: Cultural Responses to War from Both Sides of the Atlantic». Electronic Theses, Treatises and Dissertations, paper 972. 


\section{Notas}

1 Tesis doctoral «Representaciones de la Guerra de Malvinas (1982) y sus consecuencias socio-culturales en el teatro argentino (1982-2007): poéticas dramáticas, historia y memoria». Dirigida por Hugo Mancuso y codirigida por Mauricio Tossi.

2 El reclamo argentino cuenta con el reconocimiento de la Organización de las Naciones Unidas, que se pronuncia a través de la Resolución 2065 en diciembre de 1965. Allí se señala que la disputa representa un conflicto colonial y se insta a ambas partes a solucionar pacíficamente la situación. En 1976 la ONU, a través de una nueva resolución, explicita que en el caso de Malvinas no aplica el principio de autodeterminación y se vuelve a poner el énfasis en la importancia de una salida pacífica (Pastorino, 2013).

3 A la hora de hablar de posguerra y posdictadura, es posible entender el prefijo «pos-» de dos modos complementarios: 1) como lo que acontece luego de la dictadura; o 2) como lo que ocurre como consecuencia de la guerra. Privilegiamos en este caso la noción de posdictadura por sobre la de posguerra debido a que la guerra debe ser entendida no sólo en el extenso proceso histórico de la Causa sino también en el marco de la dictadura militar que la impulsa. Simultáneamente, varios procesos necesarios para pensar Malvinas trascienden la inmediatez de la guerra y se arraigan en procesos sociales más amplios, como las disputas históricas, económicas, sociales y simbólicas entre Buenos Aires y las provincias del llamado «Interior».

4 En una mirada a vuelo de pájaro sobre la bibliografía argentina se hacen presentes nombres tan diversos como los de Altamirano, Camogli, Canclini, Cardoso, Kirschbaum y Van der Kooy, Destefani, Esteban, Erlich, Escudero, Gamba, Guber, Iglesias, Lorenz, Muñoz Azpiri, Niebieskietwiat, Novaro, Palermo, Rozitchner, Yofre, etc. Cada caso de esta lista (que no posee pretensión de exhaustividad) implica formas teóricas diferentes para pensar los acontecimientos, con lecturas historiológicas, ideológicas y políticas de gran diversidad.

5 Algunos de los autores citados en este apartado aportan materiales vinculados a su investigación en «Representaciones de la Guerra de Malvinas (1982)», dossier que coordinamos para la revista AJVersus de la Universidad de Buenos Aires (R. Dubatti, 2018). 
6 Se realizan referencias a las novelas Las islas (1998) de Carlos Gamerro y La guerra del gallo (2011) de Juan Guinot. Si bien ambas son adaptadas para teatro (en 2011 y 2015 respectivamente), solo se hace mención a sus versiones originales.

7 Para nuestro análisis utilizamos el texto original, cedido por el autor. Todas las citas presentes corresponden a esa primer versión.

8 Para un análisis pormenorizado de las relaciones entre la pieza de Monti y el realismo reflexivo, remitimos al esclarecedor trabajo de Sosa (2002).

9 Martín explica: «Primero la busqué y después aprendí a llorarla. La noche que llegó Coco con un pedido del mercado, me preguntó por qué estaba llorando y sin pedir permiso se quedó... hasta ahora. Se instaló en mi vida con toda su pena a cuestas. Aceptar un dolor ajeno era menos doloroso que ocuparme de mi propio dolor. Los primeros días yo no paraba de hablar de Laura ni él de contarme del desembarco del 2 de abril» (13).

10 En consonancia con esto, Federico Lorenz sugiere en Las guerras por Malvinas (2012) que muchos ex combatientes experimentan dificultades a la hora de re-insertarse en la sociedad debido a que sus valores estructurantes - no matar, no robar, etc. - se hallaban radicalmente trastocados en el campo de batalla. De tal modo, no sería necesariamente la guerra en sí misma la que generaba esos problemas sino las fricciones entre dos concepciones marcadamente opuestas. 